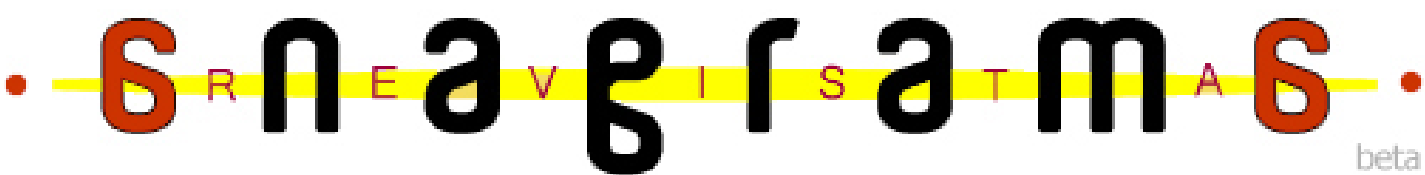

\section{Relações Públicas no Brasil: a teorização das práticas ${ }^{1}$}

\section{Aline Augusta de Oliveirz?}

\section{Resumo}

As teorias de relações públicas são diversas e existem controvérsias quanto à definição, função e campo de atuação da atividade. A atividade ainda não tem um corpo teórico completamente consolidado para defender. A proposta deste trabalho é levantar indicadores para uma reflexão, dentro do contexto organizacional atual, que busca responder às perguntas: quais teorias fundamentam a área? O que caracteriza relações públicas no Brasil? O trabalho consistiu em uma análise da bibliografia utilizada em teses e dissertações, com vistas a conhecer as principais correntes teóricas adotadas nos estudos em Relações Públicas. A conclusão a que se chega é que existe uma grande limitação de fontes, o que reforça a necessidade de mais pesquisa empírica, já indicada em vários estudos.

Palauras-chaue: comunicação, pesquisa, relações públicas, teoria

\section{Relações Públicas: teoria uersus prática}

Este trabalho teve como objetivo abordar a teorização da prática da atividade de Relações Públicas no Brasil, a partir da análise das dissertações mestrado e teses de doutorado defendidas nos Programas de Pós-graduação em Comunicação da Escola de Comunicações e Artes, da Universidade de São Paulo e da Universidade Metodista de São Paulo. A escolha destas instituições se deu pelo pioneirismo da USP na instituição do curso de Relações Públicas, pela proximidade física com a Metodista e pela tradição dos programas de pós-graduação das duas instituições.

\footnotetext{
${ }^{1}$ Síntese dos resultados do Projeto de Iniciação Científica, orientado pela Profa. Dra. Marcia Perencin Tondato.

${ }^{2}$ Graduanda de Relações Públicas na Universidade Metodista de São Paulo. Bolsista do PIBIC, programa de incentivo à iniciação científica da Universidade Metodista, em 2007. Integrante do grupo Ação RP Comunicação Estratégica, ganhador colocado em $1^{\circ}$. Lugar na classificação dos Projetos Integrados do IV semestre, com a apresentação de um Plano de Comunicação para a empresa Grupo Feital.
} 
Diversos autores discutem sobre a área de Relações Públicas e, historicamente, os aspectos práticos são preferidos aos teóricos, reforçando as deficiências apontadas por Andrade (1983), entre elas a utilização de assessoria de imprensa para a resolução de conflitos, sem existir planejamento e ações integradas com os demais setores da empresa, o que provoca o reconhecimento da atividade "apenas" como uma questão técnica, dificultando sua consolidação como campo de conhecimento.

Em 2006, a profissão de Relações Públicas completou cem anos de uma existência marcada por acontecimentos históricos, como a luta pelo fim da ditadura nos países latinos (década de 1960) e o início da chamada "nova democracia". O estudo destes cem anos nos ajuda a entender como a profissão se criou e se firmou mundialmente. Ao conhecer o "nascimento" de uma carreira temos mais parâmetros para analisarmos melhor como o seu crescimento e mudanças podem ser úteis para o desenvolvimento futuro.

\section{História das Relações Públicas no Brasil}

No inicio do século XX, enquanto a Europa está em guerra, a situação nos países da periferia é de desenvolvimento e crescimento, para o que é necessário a estruturação dos sistemas de energia e transporte. É neste contexto que vem para o Brasil, em 1914, a empresa "The Light and Power Co". Uma vez instalada, a empresa, que tinha padrões de trabalho e modo de produção canadenses e norte-americanos, sentiu a necessidade de criar um departamento de comunicação que auxiliasse na adequação dos procedimentos comunicacionais à cultura brasileira, buscando a criação de uma imagem positiva junto a este seu 'novo' público. Um departamento de comunicação instalado nas próprias dependências significava uma preocupação a mais com todas as pessoas afetadas pelo trabalho da empresa e demonstrava que ela acompanhava os acontecimentos e a eventual repercussão junto à empresa. Neste sentido, o objetivo do departamento de Relações Públicas da Light, que ficou sob a tutela do engenheiro Eduardo Pinheiro Lobo por 19 anos, era somente informar o público.

Nesta época, começo do século XX, as empresas começam a identificar a necessidade de serem bem vistas pela sociedade, em especial pelas instituições governamentais, por acionistas e pelos potenciais consumidores, percebendo a importância da construção de uma identidade e imagem organizacional. Em 1914, foi instituído o "Dia 
Nacional do Relações Públicas" pela lei $\mathrm{n}^{0}$ 7197, um possível reflexo do trabalho de comunicação viabilizado pela Light and Power ou ainda do desenvolvimento da informação institucional, trabalhada Eduardo Pinheiro Lobo, que foi declarado Patrono das Relações Públicas e, em 1975, pai das Relações Públicas brasileiras.

Em 1952, surge a primeira agência brasileira de Relações Públicas, a "Companhia Nacional de Relações Públicas”. Esta empresa prestava serviços especializados de relações públicas, estudos de formação de opinião pública e propaganda, sob a direção de Romildo Fernandes e Jorge Ignácio Penteado da Silva Telles. A Companhia mais tarde passaria a se chamar "Assessoria Nacional de Comunicação Ltda" (GURGEL, 1985). Somente na década de 1960 surgem os primeiros cursos regulares de relações públicas, em resposta a uma demanda de mercado.

O fascínio que as técnicas de Relações Públicas exerciam nas classes empresariais fez com que a Escola de Comunicação e Artes da Universidade de São Paulo, em 1966, pensasse o primeiro o curso de graduação de Relações Públicas, que começou a funcionar no ano seguinte. Neste mesmo ano, era sancionada a lei $n^{0} 5.377$ que regulamentava a profissão de Relações Públicas.

Em 1968, a General Motors do Brasil criou o Departamento de Relações Públicas, que realizou uma experiência pioneira encaminhando uma carta de apresentação do departamento recém-criado aos funcionários. Nesta apresentação, era solicitada a colaboração dos mesmos para o aprimoramento da comunicação dentro da empresa. Esta solicitação só conseguiu seis respostas, o que levou ao desenvolvimento de um trabalho de esclarecimento com a utilização de um Manual de Relações Públicas.

Entre sanções e decretos de lei que determinavam, por exemplo, a separação da atividade de Assessoria de Imprensa e Relações Públicas, o Prof. Cândido Teobaldo de Souza Andrade lançava o livro "Dicionário Profisssional de Relações Públicas e Comunicação" pela Editora Saraiva. Este livro representou uma das primeiras publicações nacionais da área, servindo como um guia aos profissionais que pouco conheciam os conceitos de comunicação.

Nos primeiros anos da década de 1980, o país se encontrava em processo de abertura política. A sociedade busca a autoconfiança e já não aceita a subordinação (TEIXEIRA, 2002). Começa então o resgate da importância da comunicação como instrumento na gestão de empresas, porém não mais como uma atividade dividida em setores como relações públicas, assessoria de imprensa e propaganda institucional. No 
aspecto conceitual, a preocupação se concentrava em definir os aspectos operacionais da atividade de Relações Públicas.

Um acontecimento marcante para a área na década de 1990 foi a realização do Parlamento de Relações Públicas, um encontro anual realizado de 1992 a 1997 envolvendo profissionais de todas as partes do país. O Parlamento possibilitou aos profissionais a manifestação de dúvidas e insatisfações acerca da profissão e promoveu uma reflexão sobre a atividade, uma readequação da profissão aos novos tempos e às novas exigências do mercado.

Do Parlamento resultou um documento no qual os profissionais definem novas funções e atividades específicas de Relações Públicas. A partir destas definições, o Parlamento cumpriu, em parte, o objetivo de democratizar a atividade e tornar a comunicação um fator estratégico fundamental para a sobrevivência da profissão no mercado. Mas mesmo assim, as reflexões continuam no âmbito da prática e para que uma área seja definida como campo científico é preciso que exista um arcabouço teórico que fundamente as práticas estabelecidas. Tendo isso em vista, é que, neste trabalho partimos da apresentação das teorias de uso mais freqüente na formação do profissional desta área.

\section{Definição de Relações Públicas}

Diversos autores definem Relações Públicas como sendo uma função administrativa da comunicação. Como definição geral existe certo consenso sobre a atividade de relações públicas estar relacionada a um planejamento estratégico do processo de comunicação nas organizações. O objetivo deste planejamento seria alinhar os interesses das organizações com os de seus públicos, de modo a conseguir a boa vontade destes, despertando a credibilidade e a confiança em seus produtos.

Para entendermos o porquê da dificuldade de conceituar "Relações Públicas", identificamos o que seja uma definição a partir da constituição de uma área. A Comunicação é um campo que sintetiza as características definidoras de sociedade na medida em que envolve, segundo Polistchuk e Trinta (2003, p. 63):

(...) um ethos, que diz respeito à atitude de quem opina ou argumenta, um logos, que se refere à racionalidade inerente à opinião ou ao argumento apresentado; e um pathos, que tem a ver com a arte de tornar apaixonante o fato mesmo de opinar ou de argumentar.

Reuista Anagrama Reuista Interdisciplinar da Graduação

Ano 1 - Edição 4 Junho/Arosto de 2008

Auenida Professor Lúcio Martins Rodrigues, Ч४З, Cidade Uniuersitária, São Paulo, CEP: 05508-900 anagramagusp.br 
E as Relações Públicas são uma área que pertence à comunicação, pois interpretam os acontecimentos e identificam as possibilidades de resolução por meio de atitudes comunicacionais. A problemática toda se resume em sistematizar este processo, criando um modelo definidor desta área.

Ao se depararem com a diversidade de conceitos de Relações Públicas conforme os diferentes autores, os estudantes da área vêem ampliadas as dificuldades naturais para quem inicia a exploração teórica de um campo. Ao pesquisar as diversas definições dos autores, parece-nos que ocorre certa contradição entre a definição da área e a especificação da atividade, com ênfase na administração dos relacionamentos estratégicos como sendo função do relações-públicas, mas também como uma definição do que pode vir a ser a área. Essa confusão deve-se à dificuldade de conciliar conceitos para exemplificar, de modo simples e conciso, o que é a área, o profissional e a atividade.

\section{Conceituando Relações Públicas}

Habermas (2003) discute amplamente o desenvolvimento do significado e utilização dos termos "público" e "opinião pública" tanto nos aspectos históricos como sociológicos. No processo de des-construção da esfera pública, ao comentar sua mudança estrutural, o autor primeiro coloca o "público" como sujeito da esfera pública, portador da "opinião pública", cuja função seria tornar público assuntos de interesse do povo, nos debates judiciais, significado que se modifica com a entrada da mídia no contexto, passando a significar um "atributo de quem desperta a opinião pública; public relations, nome com que são batizados os relacionamentos com os públicos" (HABERMAS, 2003, p. $14)$.

Para melhor conceituar a área, James Grunig e Todd Hunt elaboraram o que chamaram de modelos para descrever quatro tipos de relações públicas que acreditavam ser os mais usados em toda a história da área, tanto no aspecto teórico quanto prático da profissão (GRUNIG e HUNT, 1984, p. 21). Estes quatro modelos (agência de imprensa/divulgação, informação pública, assimétrico e simétrico) surgem de uma proposta para entender como são praticadas as Relações Públicas, simplificando o estudo das teorias e das práticas, possibilitando conhecer qual o modelo mais praticado pelas organizações. Os quatro modelos diferem um do outro em suas finalidades. 
Tanto o primeiro quanto o segundo modelo se caracterizam por serem modelos de uma mão, em que o retorno das informações não é importante e tão pouco necessário para a boa realização do trabalho. Diferente destes, os modelos "assimétrico" e "simétrico" têm como fundamento o retorno de informações e por isso são denominados "modelos de duas mãos".

Os diferentes modelos podem ser encontrados em uma única organização. Um elemento de extrema importância para a definição de qual modelo é mais utilizado e que está presente nos trabalhos de Relações Públicas é a pesquisa. Grunig e Hunt (1984, p. 24) explicam que a principal intenção dos que trabalham com Relações Públicas é informar o público de maneira dirigida e, para isso, utilizam-se de pesquisas que apontem os diferenciais de cada público. O modelo "agência de imprensa/divulgação" raramente utiliza a pesquisa, a não ser para descobrir quais informações devem constar em cada meio de comunicação e o quanto o público está satisfeito com determinado produto ou serviço. O modelo "informação pública" também utiliza a pesquisa como subsídio para formatar a comunicação para públicos abrangentes e menos conhecidos. Às vezes usam a pesquisa para verificar se a informação correta chegou ao destino pretendido, demonstrando que as organizações que praticam esse modelo não têm conhecimento da amplitude da importância da pesquisa. Em contrapartida, os modelos de duas mãos são assim nomeados, pois fazem um uso extensivo de pesquisas, dos dois tipos: formativa, que ajuda a planejar e determinar os objetivos; e avaliativa, que descobre se os objetivos foram alcançados.

O modelo assimétrico utiliza a pesquisa formativa para descobrir quais são as características dos públicos e o que eles esperam da organização, identificando políticas e metas corporativas. Com a pesquisa avaliativa, neste modelo verifica-se o retorno das informações, se a comunicação ocorreu da maneira como foi planejada e se o comportamento dos públicos foi modificado depois da campanha de relações públicas promovida (GRUNIG e HUNT, 1984, p. 25).

No modelo simétrico, a pesquisa formativa é usada para identificar o que os públicos percebem da organização e determinar as conseqüências das políticas organizacionais para estes públicos. Neste modelo, este tipo de pesquisa pode ser usado para a organização compreender e administrar a comunicação de forma a melhor atender o interesse público. E a pesquisa avaliativa é usada para conhecer a compreensão mútua entre a alta administração e os públicos atingidos pela organização (GRUNIG e HUNT, 1984, p. 25). 
Estes quatro modelos foram desenvolvidos após extensa pesquisa, a partir da qual Grunig e Hunt (1984, p.24) buscavam uma maneira mais eficaz de conduzir a comunicação das organizações. Mas com a ampliação dos estudos, estes pesquisadores percebem que definir modelos não bastava, e elaboram o que fica conhecido como Princípios de Excelência em Comunicação, a partir de pesquisa realizada ao longo de 10 anos, em cerca de 3000 empresas norte-americanas, que acreditamos não seja relevante ser descrita neste trabalho.

\section{As conceituações brasileiras}

Simões (1995, p. 13) apresenta o mundo das Relações Públicas a partir da força política da opinião pública, que exerce pressão sobre as organizações existentes no sistema social, estabelecendo sua definição, a causa da sua existência, os instrumentos utilizados, dentre outros aspectos. Simões define a profissão a partir dos aspectos conceitual e operacional. A definição conceitual enxerga as Relações Públicas como uma "ciência", na medida em que haja a preocupação com um conhecimento que permita explicar, prever e controlar o exercício de poder entre a organização e seus públicos (SIMÕES, 1995, p.43). A definição operacional procura responder à pergunta "como se exerce esta atividade?", como é realizado o trabalho comunicacional. Neste aspecto, Relações Públicas é capaz de analisar as tendências, prevendo as conseqüências das decisões a serem tomadas, agindo a partir de programas planejados de comunicação para assessorar as tomadas de decisão. No contexto da ciência, Simões define como objetos da atividade a organização e os públicos (SIMÕES, 1995, p.43).

Para Kunsch (1997, p. 113), as relações públicas funcionam de maneira integrada às demais áreas de comunicação e, juntas, formam o que é definido por "comunicação integrada“, entendida como uma interdependência das áreas de uma organização em termos comunicacionais para que haja excelência no fluxo de informações e relacionamentos.

O posicionamento de Kunsch se dá na linha de Andrade, para quem a principal (e talvez única) função específica de Relações Públicas é a responsabilidade de promover uma comunicação eficaz dentro das organizações (ANDRADE, 1983, p.97). Ao discutir a formação deste profissional, este autor apresenta como problema para reconhecimento do 
profissional da área a competência no uso do idioma nas comunicações escritas, reforçando a 'teoria' de que "rp não escreve bem". Como solução, sugere que os relações-públicas treinem sua capacidade de escrita e busquem sempre se aperfeiçoar, uma necessidade comum à maioria das profissões.

Estas definições deixam claras as divergências existentes quanto à conceituação de Relações Públicas tanto no que diz respeito aos pressupostos teóricos como quanto à atuação prática. Conforme aponta França (2003) a maior dificuldade em conceituar a atividade de Relações Públicas surge justamente da aceitação de definições originadas do meio profissionais, sem uma problematização teórica, sem a devida análise, pela academia, por princípio de onde deve partir o debate crítico sobre a essência da atividade.

\section{Metodologia}

A análise das dissertações de mestrado e teses de doutorado contribui para identificarmos o desenvolvimento das Relações Públicas no Brasil. Para isso, quantificamos as dissertações e teses defendidas nas instituições reconhecidas como as melhores do país no ensino de Comunicação: Escola de Comunicação e Artes (ECA-USP) no período de 2000 a 2006 e na Universidade Metodista de São Paulo, entre 1979 e 2006, ${ }^{3}$ o que totalizou vinte e quatro trabalhos na ECA/USP e oito na Universidade Metodista de São Paulo.

A partir das questões: Quais teorias fundamentam a área? O que caracteriza Relações Públicas no Brasil?, organizamos o material de pesquisa com a intenção de responder à pergunta-problema: "qual a bibliografia que fundamenta a produção científica na área de Relações Públicas nos últimos anos?" entendendo a bibliografia deste conjunto de trabalhos como um indicador dos interesses dos pesquisadores brasileiros em relação ao estudo teórico da atividade. O objetivo geral foi verificar o desenvolvimento teórico da atividade de Relações Públicas e sua adequação à realidade organizacional no Brasil, avaliando especificamente as temáticas mais recorrentes das obras específicas de Relações Públicas; a existência de teorias próprias no contexto brasileiro e a diversidade bibliográfica utilizada nos programas de pós-graduação das duas universidades pesquisadas.

\footnotetext{
${ }^{3}$ Decidimos analisar todos os trabalhos apresentados na Metodista pela pequena quantidade, daí a descontinuidade do período analisado. 
Os trabalhos realizados nas duas universidades pesquisadas diferem em muitos aspectos e, na busca de um denominador comum que nos ajudasse a responder os questionamentos colocados e entender a trajetória teórica da área de Relações Públicas, o primeiro passo foi fazer uma classificação por 'tipo de trabalho', 'ano de defesa', 'título dos livros utilizados na bibliografia especializada', 'autores utilizados' e 'origem dos autores utilizados' para, em seguida, proceder à categorização. O estabelecimento das categorias se deu segundo os princípios da Análise de Conteúdo, como abordagem para estudo da 'mensagem', considerando que ela expressa um sentido, que não pode ser considerado um ato isolado, mas vinculado às condições contextuais dos emissores (FRANCO, 2005, p. 13).

\section{Discussão dos resultados}

A Escola de Comunicações de Artes da Universidade de São Paulo (ECA/USP) apresenta um número maior de trabalhos do que a Universidade Metodista de São Paulo, o que é reflexo direto do tempo de existência dos dois Programas e, indireto, do perfil do corpo docente da ECA/USP, em número maior, atuando em linhas de pesquisa mais específicas à área, pela própria formação acadêmica e até experiência profissional.

O primeiro item de análise são as categorias temáticas dos livros presentes nas bibliografias avaliadas, separadas em nove categorias: a origem de relações públicas; mudanças e renovações na atividade; ensino de relações públicas; manuais, handbooks e guides; interfaces de relações públicas/outras áreas; planejamento e prática de relações públicas; cases; pesquisa em relações públicas; outras temáticas. É importante ressaltar que os resultados comentados referem-se ao registro das obras a partir de uma única citação, pois o mesmo autor é citado em diversas obras, freqüência que é comentada no item distribuição por autores. A análise das obras nacionais e estrangeiras, como também sua distribuição por autores nos ajuda a entender as linhas de pensamentos de Relações Públicas nos últimos anos. 


\section{Categorias temáticas das obras}

\section{A origem de relações públicas, mudanças e renovações na atividade e ensino de relações públicas}

É perceptível o reconhecimento da necessidade de conceituação da área pelos pesquisadores, o que, porém, ocorre sem diversidade de fontes, limitando a reflexão. A utilização de obras referentes à "Origem e conceituação" em ambas as universidades fica em torno de $26 \%$. Importante ressaltar que, na análise detalhada, durante o fichamento, verificamos a preocupação de alguns pesquisadores em conceituar a atividade, quer seja como campo teórico de estudo, quer seja em relação à prática nas organizações.

Categorizamos em "Mudanças e renovações na atividade" obras que explicitamente refletem a busca de novos caminhos para a área dentro das linhas de pesquisa trabalhadas. Neste sentido, consideramos os resultados obtidos insuficientes para a renovação necessária, reforçando a percep̧̧ão da falta de inovação e um corpo teórico restrito na área. Não existem obras atuais - edições após 1990 - que apresentem descobertas que respondam às mudanças que a sociedade como um todo vem vivendo diante das novas dinâmicas de comunicação, relacionamentos comerciais e demandas sociais.

Causa e efeito do que observamos anteriormente, verificamos que praticamente não são utilizadas obras que pensem e discutam a área no âmbito do ensino e formação dos profissionais de Relações Públicas. Só foram encontradas três obras dessa categoria em trabalhos defendidas na ECA/USP.

Como estudante da área, percebemos que, para o desenvolvimento das Relações Públicas, são necessárias teorias que apóiem os aspectos de formação do profissional na graduação. $\mathrm{O}$ que muitas vezes acontece é passarmos pela graduação sem entender a essência da área de atuação escolhida. Esta carência resulta em um profissional que fica preso à conceitos e definições superficiais, situação esta que vai se refletir no ingresso no mercado, fazendo com que muitas vezes atue em áreas paralelas às relações públicas e que serviriam como pilares para a efetividade das ações, como Marketing, ou somente em atividades operacionais, sem utilizar as possibilidades de atuação estratégica, amplamente mencionadas e detalhadas por Kunsch e Simões e outros teóricos.

\section{Planejamento e Pesquisa em Relações Públicas - prática e cases}


Por não existir muitas obras que tratem da prática da atividade nas organizações, o resultado (em torno de 10\%) para o agrupamento de obras sobre planejamento é relevante. Comparando os trabalhos das duas instituições, temos resultados bem próximos, o que significa poucas mudanças no planejamento e na prática de Relações Públicas. Na ECA/USP esse aspecto aparece com um pouco mais, talvez devido ao maior acervo bibliográfico, constituído também por autores estrangeiros. A maior presença de autores estrangeiros notada de certa forma é negativa ao desenvolvimento de um corpo teóricoprático próprio do país, dificultando o estabelecimento de uma terminologia própria o que, entre outros aspectos, o que pode prejudicar a difusão da área no ambiente corporativo.

As duas únicas obras de pesquisa encontradas são de autoria de um dos mais destacados pesquisadores de Relações Públicas, James Grunig. Elas foram utilizadas em trabalhos realizados na ECA/USP, o que indica uma preocupação dos pesquisadores em apresentar informações atuais sobre o tema de sua pesquisa. A representação da categoria "Cases" se restringe a uma obra em cada instituição pesquisada. Estas obras são utilizadas na medida em que é necessária uma complementação para desenvolvimento do tema do trabalho, explicitando a perspectiva da comunicação e das relações públicas fora do Brasil e num futuro próximo.

\section{Uso de Manuais, Handbooks, Guides}

No geral, a presença desta categoria é semelhante nas duas instituições analisadas, em torno de 12\%. Em números absolutos, é visível a maior utilização nos trabalhos defendidos na ECA/USP. Vale lembrar que muitos destes guias são importados, o que indica uma falta de cultura da comunidade acadêmica brasileira na produção deste tipo de obra.

\section{Interfaces Relações Públicas/outras áreas e outras temáticas}

O agrupamento de obras que apresentam Relações Públicas no contexto de outras áreas - política, governamental, educação, jornalismo - demonstra a preocupação dos pesquisadores em ampliar as perspectivas de estudo, respondendo talvez às transformações 
das dinâmicas das organizações e à complexidade da sociedade atual como um todo. A ECA/USP apresenta maior quantidade absoluta de obras classificadas nessa categoria.

Este resultado é um indicador positivo para identificação de Relações Públicas não somente pela ação operacional, mas também como uma área estratégica, na medida em que interage com outras áreas, não só de comunicação, mas da empresa como um todo, respondendo aos princípios de comunicação integrada defendidos por Kunsch.

\section{Uso de autores nacionais $K$ autores estrangeiros}

Verificamos que os trabalhos realizados na Universidade de São Paulo apresentam um equilíbrio no uso de autores nacionais e estrangeiros. Acreditamos que isso acontece devido ao maior acervo e possibilidade de integração com outras universidades fora do país e maior incentivo em pesquisas acadêmicas por parte da USP. Já os trabalhos da Universidade Metodista de São Paulo se caracterizam pela maior presença de obras nacionais, um resultado que mostra uma restrição bibliográfica da instituição, além de caracterizar a cultura do estudante, que restringe a pesquisa a uma única biblioteca, não ampliando a busca em outras fontes.

\begin{tabular}{|l|c|c|c|c|}
\hline \multicolumn{4}{|c|}{ Tabela 1 - NACIONAIS X ESTRANGEIROS } \\
\hline & \multicolumn{2}{|c|}{ USP } & \multicolumn{2}{c|}{ Metodista } \\
\hline & Freq. abs. & \% & Freq. abs & $\%$ \\
\hline Autores Nacionais & 144 & $55,38 \%$ & 84 & $63,64 \%$ \\
\hline Autores Estrangeiros & 116 & $44,62 \%$ & 48 & $36,36 \%$ \\
\hline TOTAL & $\mathbf{2 6 0}$ & $100,00 \%$ & $\mathbf{1 3 2}$ & $100,00 \%$ \\
\hline
\end{tabular}

Os autores mais citados são Cândido Teobaldo de Souza Andrade, um dos pioneiros da atividade no Brasil e autor das primeiras obras que definem as Relações Públicas; James Grunig, pesquisador que busca conceituar a área a partir da prática, com pesquisas que são referências na prática e no ensino de Relações Públicas. NE seqüência, Margarida M. K. Kunsch, consultada principalmente pelos seus estudos em comunicação integrada, concentrando-se na temática do Planejamento, além de obras de caráter de quantitativo sobre a produção científica. Outro autor citado com destaque é Roberto Porto 
Simões Portador, que trabalha a área a partir de um aspecto político Cerca de $80 \%$ são classificados em "Outros", pois as obras consultadas se distribuíam entre diversos autores, mostrando uma pulverização dos estudos.

\begin{tabular}{|l|c|c|}
\hline \multicolumn{3}{|c|}{ Tabela 2 - DISTRIBUIC̃O POR AUTORES } \\
\hline & Freq. abs. & \% \\
\hline Cândido T. de S. Andrade & 9 & $7,26 \%$ \\
\hline James Grunig & 7 & $5,65 \%$ \\
\hline Margarida M. K. Kunsch & 5 & $4,03 \%$ \\
\hline Roberto Porto Simões & 2 & $1,61 \%$ \\
\hline Outros & 101 & $81,45 \%$ \\
\hline TOTAL: & $\mathbf{1 2 4}$ & $100,00 \%$ \\
\hline
\end{tabular}

\section{Considerações finais}

Diversos autores nos dizem que o saber acontece na confluência do que entendemos como prática e de sua sistematização, ou seja, a teoria. A pesquisa realizada buscou verificar, a partir de um pequeno recorte de análise bibliográfica, como isso acontece na área de Relações Públicas no Brasil e o resultado enfatiza aquilo que estudantes de graduação sentem no dia-a-dia: uma dificuldade de conceituação teórica, apesar da abrangência de atuação prática. Ao nos aproximarmos dos teóricos brasileiros, e das pesquisas, verificamos uma ênfase na afirmação sobre a importância da atividade para as organizações e destaque dos aspectos operacionais, porém, partindo de definições que não se reportam aos princípios teóricos do campo da comunicação.

Um dos aspectos de destaque é a carência de obras que expliquem o que é a atividade no contexto do ensino de graduação, que problematizem o trabalho dos professores desta área, e que, em um certo sentido, oriente os estudantes quanto à aquisição de conhecimento no contexto da formação acadêmica e profissional, enquanto na graduação. Indo mais longe, acreditamos que tal base serviria até como incentivo aos formandos e jovens profissionais para um maior empenho em pesquisas na área, contribuindo para superar algumas das deficiências de produção na área neste trabalho apontadas. Em outro sentido, a falta de pesquisas também é preocupante tendo em vista sua importância em Relações Públicas, uma área que lida diretamente com a opinião pública, 
um tema complexo, que oferece várias vertentes de exploração e apresenta inúmeras variáveis para sua compreensão.

Os resultados demonstram o quanto as Relações Públicas são difundidas no Brasil e a importância de as universidades oferecerem subsídios aos estudantes quanto ao conhecimento de todas as visões sobre a área. A partir da categorização das obras de trabalhos defendidos Universidade de São Paulo e na Universidade Metodista de São Paulo, verificamos a limitação bibliográfica e a baixa produção acadêmica. Acreditamos que se as mesmas obras se repetem nos trabalhos ao longo dos anos analisados, para diferentes temas de pesquisas, sem que haja acréscimo de novos títulos ou mesmo autores diferentes, é porque não há um incentivo ou interesse em sistematizar descobertas, ou mesmo questionar práticas.

Estas considerações nos indicam apenas um caminho, a necessidade de um maior empenho no incentivo à pesquisa e sistematização do conhecimento no país no que diz respeito às Relações Públicas. Trabalhos inéditos recentes discutem o posicionamento da atividade, a necessidade ou não de regulamentação e até mesmo, a adequação como uma área do saber, mas sim talvez uma subárea dentro do campo da comunicação (FRANÇA e FERRARI, p. 3, 2007).

Tendo isso em vista, vemos como importante e urgente a abertura deste debate entre os interessados, incluindo estudantes de graduação, futuros pesquisadores e profissionais. Como continuidade deste trabalho levantamos os seguintes caminhos:

- análise de conteúdo dos trabalhos de pós-graduação, buscando especificar as lacunas de pesquisa;

- levantamento, em anais de congressos, dos trabalhos ainda inéditos nas editoras;

- sistematização das linhas de pesquisa dos programas de pós-graduação;

- levantamento das pesquisas e publicações sobre o desenvolvimento conceitual dos aspectos relacionados à área: públicos, terminologia, áreas de atuação;

- pesquisa junto ao mercado para avaliação da prática e conseqüente aprimoramento da teoria. 


\section{Bibliografia}

ALVES-MAZZOTTI, Alda Judith e GEWANDSZNAIDER, Fernando. O método nas ciências naturais e sociais - pesquisa quantitativa e qualitativa. São Paulo: Pioneira, 1998.

ANDRADE, Candido Teobaldo de Souza. Para entender Relações Públicas. São Paulo: Loyola, 1983.

BARROS, Antonio (org.) Métodos e técnicas de pesquisa em comunicação. São Paulo: Atlas, 2005

FERRARI, Maria Aparecida. Os efeitos dos valores organizacionais na determinação da prática e do papel dos profissionais de relações públicas - estudo comparativo entre organizações do Brasil e do Chile. Tese defendida na ECA-USP, em 2000.

FONSECA Jr., Wilson Corrêa da. "Análise de conteúdo". In: DUARTE, Jorge e BARROS, Antonio (org.) Métodos e técnicas de pesquisa em comunicação. São Paulo: Atlas, 2005.

FRANÇA, Fábio e FERRARI, Maria Aparecida. "Reflexões sobre uma nova proposta de classificação da comunicação e de suas áreas". Trabalho apresentado no VII Encontro dos Núcleos de Pesquisa em Comunicação - NP. Relações Públicas e Comunicação Organizacional do XXX Congresso Brasileiro de Ciências da Comunicação - Santos, 29 de agosto a 02 de setembro de 2007.

FRANCO, Maria Laura P. B. Análise do conteúdo. Brasília: Líber Livro, 2005.

GRUNIG, James, TODD, Hunt. Managing Public Relations. New York, Holt, Rinehart \& Winston, 1984.

GURGEL, J. B. Serra e. Cronologia da evolução histórica das relações públicas. 3. ed. Brasília: Linha Gráfica, 1985. 
HABERMAS, Jurgen. Mudança estrutural da esfera pública. $2^{\text {a }}$. edição. Rio de Janeiro: Tempo Brasileiro, 2003.

KUNSCH, Margarida Maria Krohling. Relações públicas e modernidade: novos paradigmas da comunicação. São Paulo: Summus, 1997.

LESLY, Philip. The Nature and Role of Public Relations. Public Relations Handbook. $2^{\mathrm{a}}$.ed. New Jersey - USA: Prentice Hall. 1978.

POLISTCHUK, Ilana e TRINTA, Aluízio Ramos Azevedo. Teorias da Comunicação: O pensamento e a prática da comunicação social. 2. ed. Rio de Janeiro: Elsevier, 2003.

SIMÕES, Roberto Porto. Relações públicas: função política. 3.ed. Porto Alegre: Sagra, 1995. 197p.

TEIXEIRA, João Evangelista. Relações Públicas na UMESP: trinta anos de história. João Evangelista Teixeira. São Bernardo do Campo: UMESP, 2002. 